\title{
Social Media Marketing and Bank Customers' Behaviour: Conceptualizing a Relationship Model
}

\section{C.D Mudondo ${ }^{1}$, K K Govender ${ }^{2}$}

${ }^{1}$ Great Zimbabwe University

${ }^{2}$ School of Management, IT and Governance University of KwaZulu-Natal

Article History: Received: 10 November 2020; Revised: 12 January 2021; Accepted: 27 January 2021; Published online: 05 April 2021

\begin{abstract}
While research has underscored the benefits of social media marketing (SMM), organisations including commercial banks still fail to justify their continued investment in SMM, mainly because the full impact (of SMM) on customer behaviour remains unclear or largely researched. Thus, the aim of this paper was conduct an extensive literature review to develop a conceptual model to depict the proposed impact of social media marketing on commercial bank customers' behaviour from a Social Exchange Theory (SET) perspective. Through an extensive review and synthesis of the literature on SMM, the researchers were able to theoretically postulate and propose the (possible) influence of the SET determinants inherent in SMM on commercial bank customers' satisfaction, loyalty and their repurchase intentions. It is recommended that bank managers and marketers take cognizance of these (possible) proposed relationships, more specifically, the influence of the SET determinants inherent in SMM on bank customers' behaviour. Furthermore, there is need to empirically evaluate the proposed conceptual model using data from a sample of bank customers and inferential statistics analytical techniques.
\end{abstract}

Keywords: marketing communication; social media; bank customers, conceptual model

\section{Introduction}

The term SM has drawn remarkable attention amongst marketers and, in the process, has created excitement, confusion and debate as to how it should be conceptualized in research (Gruner and Power, 2017). Most research studies on SM have focused on specific SM platforms such as Facebook (Rauniar et al., 2014 ), and Twitter (Lim et al., 2014), which implies that SM can be defined as that particular and individual SM platform under study and as such, the findings and conclusions drawn from these studies would be limited to the specific SM platform, thereby limiting the generalisability of the research results. Thus, in this study, the researchers depart from the abovementioned approach and concur with Kim's (2016) approach which considers all platforms or social media sites as one and constitute what in this research is referred to as SM. This position is informed by the argument that when using SM to reach potential customers, companies can use multiple platforms simultaneously, whilst customers who use SM do not restrict themselves to a single social network site but may employ various social platforms concurrently (Karikari, Osei-Frimpong and Owusu-Frimpong, 2017).

The preceding decade has witnessed marked developments and an increase in the popularity of social media (SM) among both organisations and consumers, all of which has impacted various business processes, especially the marketing landscape (Cesaron and Consoli, 2015). This view is supported by Karikari, Osei-Frimpong and Owusu-Frimpong (2017) who acknowledge that SM has created complex and intricate social interactions worldwide, which have allowed online SM users to create online communities. In these 'communities' consumers share updates and can at will, "be-friend" or "de-friend" a contact (Ngai Tao, Spencer, Moon and Karen, 2015:770). The above authors note that the power of SM has transformed both personal and organisational interactions, creating active, sophisticated and empowered customers who are not easy to manipulate, influence, persuade and retain (Constantinides, 2014). Thus, $21^{\text {st }}$ century firms and brands are presented with a colossal task to re-strategise and manage the 'new' customer.

It is important to observe that today's firms have immensely benefitted from SM, since the SM platforms allow businesses to forge links with their markets (Charlesworth, 2014), as well as learn about the customers' needs and opinions, while interacting with them more directly and in a personalised manner (Kane, 2015). Saridakis, Benson, Ezingeard and Tennakoon (2016) concur with the preceding observation and assert that society has generally accepted the use of SM as a norm and has adopted it not only for communication, interaction and networking among individuals, but also allowing organisations to engage, interact and connect with customers.

Dawayan and Sondoh (2015), stress that for organisations to gainfully use SM, it is crucial to have a carefully planned strategy on how to maximise its benefits. In underscoring the importance of a planned strategy, Manyang (2017) affirms that an effective approach to develop a SM marketing strategy, is to formulate clear 
goals and outline success metrics before launching, so as to be able to identify the targeted SM audience and customize the SM content accordingly.

It is against the above background that this paper explores (conceptually), the impact of SM on commercial banks.

\section{Social Media and Social Media Marketing}

The advent SM as a Web2.0 innovation has seen many firms using SM, inter-alia for "market research and feedback generation; publicity, branding and reputation management; business networking; and customer service and customer relationship management" (Thoring, 2011:143). According to Ahmed (2017:2), "SM allows users to connect with peers by adding them to networks of friends, which facilitates communication particularly among peer groups"; and in the process building social capital which contributes to the user's well-being since SM offers an alternative communication route that addresses a social need (Ashely and Tracy, 2015).

Kumar and Mirchandani (2012) argue that SM enables the creation of communities which are regularly formed by online users who have common interests and backgrounds and it allows interaction, communication and engagement within these communities. Unlike the traditional media where communication is uni-directional and the context is created by the firms, in SM, communication may be bi-directional or multi-directional and it is based on user-generated content where consumers are the sources of information (Constantinides and Fountain, 2008). According to Huang et al. (2017:43), "Bi-directionality means that both sides understand the meaning of each other's expression and are willing to engage with each other when interacting with colleagues through social media."

Mayfield (2008:49) states that "connectedness involves integration whereby sites, resources, and people are connected through links which are shared by other users on various social media platforms". By their multidirectional nature, SM platforms allow for feedback and active participation by users who are free to 'be-friend' or 'de-friend' their contacts and can edit, create, communicate and comment on the contents (Mayfield, 2008).

Tuten (2008 cited in Ahmed, 2017:2), defines SMM as "a form of online advertising that uses the cultural context of social context, including social networks (e.g., YouTube, Myspace and Facebook), virtual worlds (e.g., Second Life, and Kaneva), social news sites (e.g., Digg and del.icio.us), and social opinion-sharing sites (e.g. Eopinions), to meet branding and communication objectives". Chikandiwa, Contogiannis and Jembere (2013:87) note that SMM is a "system which integrates social media principles with marketing communication elements in an effort to create strong and lasting relationships". SMM enables customer engagement, interaction, collaboration and harnessing information for the purpose of the marketing of products and services. SMM involves the conversion of customers and consumers into marketers and advertisers and the provision of channels not only to share and evaluate content but to network with friends and strangers as well as interact with brands and share experiences (Chang and Hsu, 2016).

Felix, et al. (2016:6) argue that in general, companies using SM are likely to "choose (intentionally or unintentionally), a position somewhere between the poles on each dimension". Furthermore, the above researchers state that SM "provides firms with an opportunity to use social media to build relationships with customers, employees, communities, and other stakeholders (i.e. when they act as explorers)" (Felix, et al., 2016:6). At the same time, Felix, et al. (2016:6) state that organisations may view SM "as simply another communication channel through which they can push information to customers (i.e. when they act as defenders)".

The primary objectives of SMM include, inter- alia, "stimulating sales, increasing brand awareness, improving brand image, generating traffic to online platforms, reducing marketing costs, and creating user interactivity on platforms by stimulating users to post or share content". Kim (2016) posits that SM platforms and networks have significantly changed the way customers acquire information, their way of communication, the way they use it and their entire lifestyles. SM has allowed for the formation of ubiquitous online social interactions where customers and consumers create online communities, share information and can friend or defriend their community members as per need or circumstances (Curras-Perez, Ruiz-Mafe and Sanz-Blas, 2014).

The Accenture Report (2014) states that firms in the financial services sector may exploit opportunities presented by SM if they aptly understand their social audience and the firms' SM goals and limits, map 
consumer needs into meaningful and beneficial social experience and ensure that they have the correct capabilities to continuously and consistently deliver.

It is important to observe that while many researchers generally agree on the impact, importance and prominence of SM as an effective research-purchase channel, a YouGov (2014) survey report reveals the downside of SM in as far as consumer purchase is concerned. The aforementioned survey reported that SM may be less influential and effective in digital marketing as evidenced in the 2014 UK survey, which revealed that $55 \%$ of online shoppers negatively perceived an outlet with social media presence, suggesting that they do not entirely trust the SMM efforts of some of the firms they interact with. However, in spite of these negative perceptions and attitude towards SMM, extensive research has also overwhelmingly revealed that the use of SM platforms by online customers has been on the increase as reflected in Figure 1.

\begin{tabular}{|c|c|c|c|c|c|c|c|c|}
\hline & $\begin{array}{l}\frac{9}{8} \\
\\
\end{array}$ & 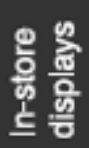 & 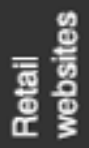 & 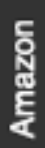 & 咅営 & $Z$ & 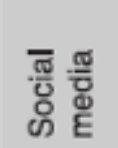 & $\frac{\text { 응 을 }}{\frac{0}{2}}$ \\
\hline Car parts & 1 & 2 & 3 & 5 & 4 & 6 & 7 & 8 \\
\hline Clothing & 3 & 2 & 1 & 4 & 5 & $\begin{array}{c}6 \\
\text { (equal) }\end{array}$ & $\begin{array}{c}6 \\
\text { (equal) }\end{array}$ & $\begin{array}{c}6 \\
\text { (equal) }\end{array}$ \\
\hline Electronics & 1 & 4 & 3 & 2 & 5 & 7 & 6 & 8 \\
\hline $\begin{array}{l}\text { Fumiture/ } \\
\text { houseware }\end{array}$ & 1 & 3 & 4 & 2 & 5 & $\begin{array}{c}6 \\
\text { (equal) }\end{array}$ & $\begin{array}{c}6 \\
\text { (equal) }\end{array}$ & $\begin{array}{c}6 \\
\text { (equal) }\end{array}$ \\
\hline Groceries & 4 & 1 & 3 & 5 & 2 & $\begin{array}{c}6 \\
\text { (equal) }\end{array}$ & 7 & $\begin{array}{c}6 \\
\text { (equal) }\end{array}$ \\
\hline $\begin{array}{l}\text { Home } \\
\text { improvements }\end{array}$ & 2 & 1 & 3 & 4 & 5 & 6 & $\begin{array}{c}7 \\
\text { (equal) }\end{array}$ & $\begin{array}{c}7 \\
\text { (equal) }\end{array}$ \\
\hline $\begin{array}{l}\text { Sporting } \\
\text { goods }\end{array}$ & 1 & 3 & 2 & 4 & 5 & $\begin{array}{c}6 \\
\text { (equal) }\end{array}$ & 7 & $\begin{array}{c}6 \\
\text { (equal) }\end{array}$ \\
\hline Toys & 1 & 4 & 3 & 2 & 5 & 6 & $\begin{array}{c}7 \\
\text { (equal) }\end{array}$ & $\begin{array}{c}7 \\
\text { (equal) }\end{array}$ \\
\hline
\end{tabular}

Figure 1. How consumers research and buy across several product categories Source: Charlesworth (2014:10).

\subsection{Current Developments in Social Media Marketing}

Stanic and Hansson (2017) posit that digitalisation and the increase in SM have significantly transformed the interaction among customers, as well as between customers and their brands and firms. It is argued that there has been an exponential rise in the use and adoption of SM (Karikari, Osei-Frimpong and Owusu-Frimpong, 2017), with statistics on the global use of FB and Twitter revealing that it stands at over a billion mark. The Social Media Marketing (SMM) industry report (Stelzner, 2017) indicates that the number of SM users globally in 2016 had gone beyond the 2 billion mark, and was projected to reach 2.44 billion by 2018 a target that has since been surpassed.

The Digital Banking Report (2014) reveals that in 2014, SM penetration globally is on the increase, with more than 50 percent in North America, 83.8\% penetration for Middle East and Africa, while Central and Eastern Europe stands at $75.9 \%$. In Latin America, South America, Asia-Pacific and Western Europe, SM penetration stands at $74.9 \%, 67.5 \%, 68.6 \%$ and $65.1 \%$ respectively. In the report, it is stated that one third of global consumers use information from SM sites (FB, Twitter) to evaluate bank products and services. According to Gallup (2014, cited in Ahmed, 2017:2) "Globally, more than $50 \%$ of social media users follow brands on social media and $29 \%$ follow trends and find product reviews and information, and $20 \%$ comment on 
what's hot or new or to review products, while in Malaysia social media penetration is $64 \%$, which is considered one of the highest in Asia Pacific region - second only to Singapore". This growth trajectory is echoed by reports which state that 2.46 billion people, who are a third of the global population, use social media network sites once in a month (eMarketer, 2017). Figure 2 reflects the estimates and projected estimates of social network (SN) users and penetration globally from 2016 - 2021. It must be pointed out that the estimates reflected in Figure 2 are based on information or data from sources such as regulatory and research firms, growth trends and patterns of major social network sites, digital mobile adoption trends as well as demographic and socio-economic factors which are related to specific countries.

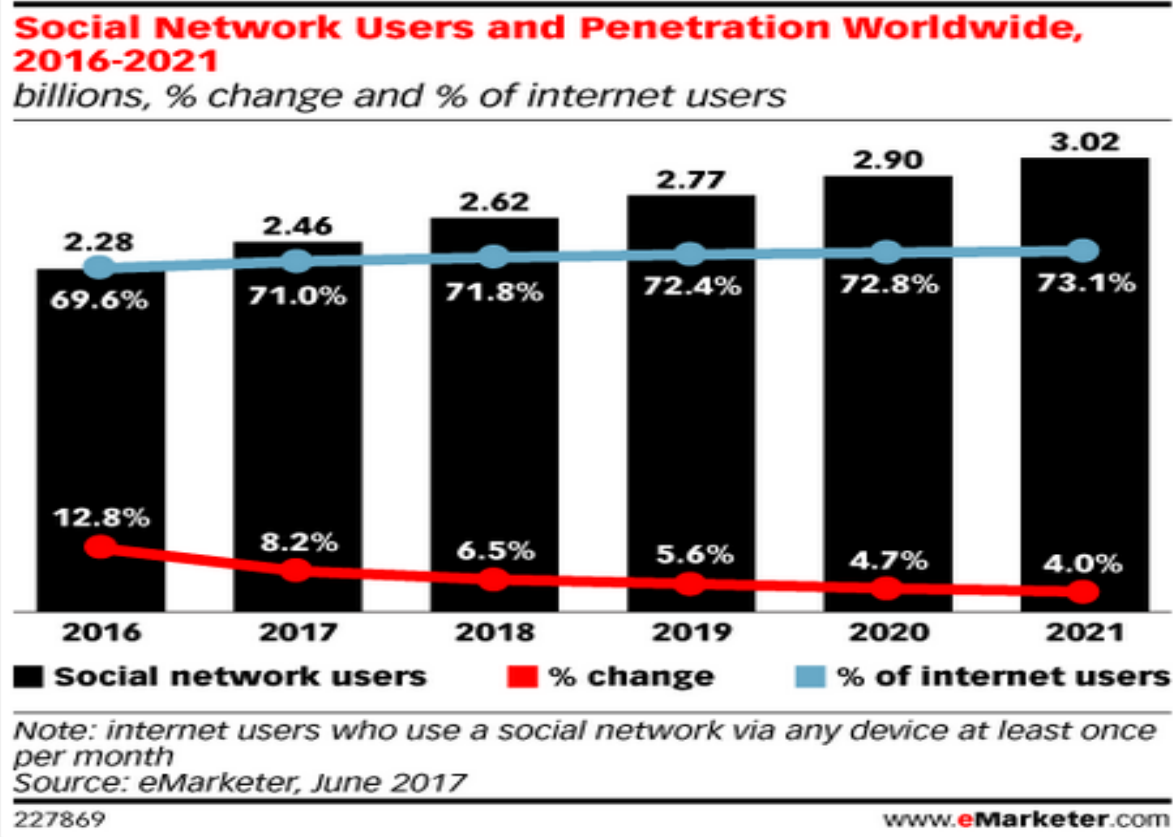

Figure 2. Estimates and projected estimates of social network (SN) users and global penetration from 2016 2021.

Source: eMarketer.com

The upsurge in the use of SM depicted in Figure 2, which is projected to 2021, is largely attributed to among other factors, easy access to WIFI, the continued expansion of $3 \mathrm{G}$ and $4 \mathrm{G}$ networks and the widespread availability of smartphones worldwide (eMarketer, 2017). The growth trajectory for 2017 was put at $81.8 \%$ of SN users globally which is anticipated to increase to $86.7 \%$ by 2021 . According to the Pew Research Global Attitudes Project (2014), 78\% of internet usage in Africa is for SM, and this has in turn generated an estimated $\$ 14$ billion social media industry which is projected to contribute \$230 billion in GDP by 2025 .

\subsection{Social Media Marketing in the Banking Sector}

Globally, the banking environment has become highly competitive largely due to ever-changing developments in digital technology (van Deventer et al., 2017, Ernst and Young, 2017). The Standard Bank (2015, cited in van Deventer et al., 2017) supports this argument and acknowledges that banks have to continuously keep up with the shifts in consumer behaviour influenced by advances in information technology which have drastically affected the interaction between banks and their customers. As such, in order to survive and remain relevant, banks are expected to increasingly innovate and transform for the future. It is against this background that the global banking sector has embraced SMM which involves the use of SM channels to promote its products or services.

In their research on Digitalization in Retail Banking: Differentiation and Standardization Through IT, van Deventer et al. (2017) argue that it has become imperative for banks to be in the same space as their customers and this has resulted in banks increasing their presence on SM channels. According to a 2016 study on the state of Social Media in Banking, "banks are using various social media channels to inform, educate, entertain and celebrate" (American Bankers Association, 2017:5). This observation is supported by Debono (2013) who asserts that SMM allows for the induction of brand awareness, enhancing the viral spread of brand messages as well as brand democratisation, allowing customers to actively interact with the brand, fostering loyalty and promoting brand reputation while driving sales and profits up. The American Bankers Association Report 
provides further credence to the preceding observation by stating that SM platforms have assisted in transforming "bank personas from anonymous institutions into friendly and approachable members of the community" (American Bankers Association, 2017:5). In the above report, Jill Castila, the President and CEO of Citizens Bank of Edmond remarks that "with great content and strategy, banks can win big with SM, reaching customers in an engaging, interactive and personal way." This view is supported by (Park and Oh, 2012) who argue that SMM is an instrument used to enhance brand image through continuously churning out positive images of the brand, products and services via various SM channels or platforms. As cited by Chikandiwa, Contogiannis and Jembere (2013), the 2011 Ernst and Young Report highlights that SMM assists banks in reclaiming any trust that customers may lose due to challenges brought about by developments such as e-banking or problems arising due to economic crises. As such, it may be argued that while challenges exist in the banking sector, there is evidence that SMM enhances the development of customer relationship management which may generate the much-needed competitive advantage for the sector. Regardless of whether an organisation (banks included) decides to actively participate in any conversation or not, its customers and others will always comment on or about the organisation through SM. Constantinides et al. (2010) assert that SM users do not only generate, edit and share information about brands, but can also create online social communities and networks where information is shared beyond the firm's control. It is important to underscore that SM is not only multidirectional but is user-generated where content and communication are created and shared by consumers rendering the firm vulnerable to users' opinions, attitudes and whims.

In spite of the benefits and significant role SM plays in deepening customer relationships, enhancing brand awareness as well as improving the firm's understanding of customer needs, the question that begs an answer is whether banks, globally, are taking full advantage of SM as the vehicle to address the research objectives. The results from the American Bankers' Association research study indicate that:

- $76 \%$ of the respondents agree or strongly agree that SM is important to their banks;

- $14 \%$ were ambivalent - neither agreed or disagreed;

- $10 \%$ indicated that SM was not important to the bank;

- 9\% said their banks do not use SM; and

- 5\% said their banks had plans to use it in 1-2 years (American Bankers Association, 2017:5).

The above findings are further reinforced by the results from the 2014 E-consultancy research carried out in the United Kingdom, which concluded that more and more banks and many other companies are integrating SM platforms into their customer relationship management systems (Friedlein, 2014). The Bloomberg Markets Report (2015) states that in China, SM platforms such as WeChat and WeBank, have led the way as banks are using them as alternatives to on-line banking. A study by Vejacka (2017) on SMM and marketing in the Slovak banking sector highlights that SM is now considered as an important marketing instrument by Slovak banks. Furthermore, in their study on the adoption of SMM in South African banks, Chikandiwa, Contogiannis and Jembere (2013) reveal that while the usage of SM is still in its infancy, Facebook and Twitter are the main platforms used by banks for marketing purposes. In addition, the findings from the research by Mutero (2014) on the effects of SM on the financial performance of commercial banks in Kenya, indicate that Kenyan banks have slowly accepted and embraced SM, with Facebook being the main platform generally used for communication between the banks and their customers. The same trajectory has also been evident in Zimbabwe where Facebook seemed to be dominating the SM space in spite of a remarkably slow uptake of SM by commercial banks (TechZim, 2012).

While the above findings may not necessarily be adequately representative, it does allow for a general conclusion to be made, namely, that banks the world over have embraced SM platforms as an effective channel for customer interaction, marketing and sales of products, introducing co-creation processes in new product development which enables customers to feel part and parcel of the bank thereby fostering and enhancing customer loyalty (Das and Chen, 2007). This view is supported by Kotler and Armstrong (2011) who posit that SM platforms are the most effective channels which facilitate customer service functions, such as responding to customer questions and enquiries, checking customer records and profiles, tracking orders and resolving customer disputes.

\subsection{Consumer Behaviour and Social Media Marketing}

Consumer behaviour can be explained from the perspective of various social and behavioural theories. The literature reveals that the diversity of these theories has enabled researchers to employ them in different contexts as determined by their perceived relevance and as dictated by the research objectives. It may be argued that the select theories provide plausible insights into the exchange process, relationships and interactions between and 
among SM users and the brands they engage with. More specifically, with respect to understanding the impact of social media marketing on consumer behaviour in general and commercial bank customers in particular, the conceptual model draws heavily from inter-alia, theories in sociology, communication, psychology as well as computer and information sciences, which relate to the dynamic and complex interactions inherent in social media. The following, namely, social exchange theory, social capital theory, social network theory and the theory of reciprocal action will be briefly explained, since the researchers are fully cognizant that these theories are elaborate and beyond the scope of the purpose and length of this paper.

\subsubsection{Social Exchange Theory}

Cropanzano, Anthony, Daniels and Hall (2016:1) state that Social Exchange Theory (SET) is "one of the most enduring conceptual paradigms prominently used in such fields as sociology, social psychology and lately management sciences". SET was used by Ko and Hur (2014) to study of the influence of employee benefits, managerial trustworthiness and procedural justice on job satisfaction, while Gilstrap and Collins (2012) used it to study the relationship between supervisor trustworthiness and job satisfaction.

The use of SET to explain the complex and dynamic nature of the relationships inherent in SMM is based on the rationale that SET is the psychological and sociological concept upon which SMM is premised and that human behaviour and attitude are directed and influenced by certain norms and customs, which influence the exchange process. The social behaviour in SMM is a culmination of an exchange process where each party in either a customer-firm or a customer-customer on-line interaction, seeks to maximise benefits and minimise costs.

It is important to highlight that the principle of exchange is central to both the SET and the marketing discipline, with the latter being defined as an activity that involves an exchange between parties controlled by non-contractual mechanisms (Lambe et al., 2001). As alluded to earlier, the fundamental premise of SET lies in the notion that human behaviour and attitude are directed and influenced by certain norms and customs which influence the exchange process. According to SET, individuals participate in a series of mutually dependent interactions that create obligations among the exchange parties and as individuals interact, they create new associations whilst they retain and maintain old relationships which they consider (Lai et al., (2014). However, it is important to note that individuals are likely to disassociate themselves from a relationship if they determine it being unprofitable to them (Lai et al., 2014: 32). It is posited that companies such as banks use the history of exchange interactions between the firm and its customers and among customers that are developed over a period, to project possible future benefits or costs of developing and sustaining such relationships.

While taking cognisance of the preceding weaknesses, it needs to be pointed out that the use of SET in this research is primarily informed by the rationale that it is the psychological and sociological theory upon which SMM is premised (Charlesworth, 2014:10). Mitchell et al. (2012) suggest that the social behaviour in SMM is a culmination of an exchange process where each party, in either a customer-firm or customer-customer on-line interaction, seeks to maximise benefits and minimise costs. Both SMM and SET depend on a network of acquaintances among which social exchanges take place (Charlesworth, 2014). Charlesworth (2014:10) further argues that "if the ability and need to communicate is hard-wired into the human brain, so too is sharing and social bonds". These social bonds and acquaintances are heavily dependent on both strong and weak relationships among and within communities and networks. In today's business environment, these relationships manifest through various social media applications such as Facebook, Twitter, Instagram and YouTube among others. These SMM platforms have converted consumers from soundless, secluded and obscure persons, into a loud, communal and unrestricted non-geographic collective which gathers in groups or publics based on a set of shared relationships, sharing their interest and affection for a brand or exchanging valuable brand information and knowledge (Patterson, 2012). These interactions have seen consumers as individuals and as communities, and companies have connected in unique and meaningful ways.

In light of the above, in this paper, the researchers propose that SET determinants in SMM (namely, trust, perceived benefits, social interaction, commitment and sociability) influence bank customers' behaviour. Through proposing the above, the researchers suggest new insights on the relevance and aptness of the social exchange principles within SMM.

\subsubsection{Social Capital Theory}

Buttressing the Social Exchange Theory, is the Social Capital Theory (SCT) which is defined as "the sum of the actual and potential resources embedded within, available through, and derived from the network of 
relationships possessed by an individual or a social unit" (Zhao et al., 2016:192). SCT includes the concept trust, which "is a relational capital element that describes the level of trust among the members through prolonged interaction" (Zhao et al., 2016:46). The SCT has been linked to SMM, with Lee et al. (2014) asserting that the benefits associated with social capital outcomes are related to the frequency and intensity with which SM platforms such as Facebook and Twitter are used, either by firms or individual users. This implies that the more frequent users of SM perceive greater social capital benefits such as information search, the more trust they will have in the social network. Other critical social capital benefits social media users seek to attain include sharing knowledge and receiving information about firms' brands and products (Patterson, 2012). Moreover, users assist one another with regards to brand-related challenges and questions and consult with others about purchase decision making (Hutter et al., 2013). SCT proposes that an individual's network of social relationships may become the premise for the generation of goodwill, which may lead to the individual or collective belonging to such a network, enjoying benefits or outcomes such as influence, information and solidarity (Kwon and Adler, 2014). To this end, it must be underlined that an individual or collective in a specific network of relationships has the impetus to invest in those relationships with other active participants in anticipation of both economic and social advantages, also referred to as intangible and tangible resources, such as gaining more trust in the network users, emotional and physical support and accessing valuable information (Appel et al., 2014).

It is plausible to argue that the integration of SM platforms in the marketing of bank services and products is considered to enhance their performance. Therefore, investigating the impact of SCT factors such as perceived benefits, social ties and trust which are inherent in SMM, on bank customers' behaviour is an important research agenda.

\subsubsection{Social Network Theory}

The Social Network Theory (SNT) is primarily rooted in the network theory which has been overtly used in psychology and sociology to examine human social organisation (Scott, 2012). According to Shafie et al. (2011), the SNT regards or defines social relationship as premised on nodes and ties, where a SM user or follower is considered a node of the network and the exchanges or interactions among users are viewed as links between and amongst them (Maiz et al., 2016). To this end, SM platforms or sites such as FB, Twitter, Instagram and YouTube provide users (nodes) with the opportunity to communicate, engage and share their content and in the process give birth to social communities where members develop both weak and strong relationships (ties) while receiving and creating content (Godes and Mayzlin, 2009).

According to Maiz et al. (2016), the SNT lauds social interaction as a 'social reality' where individuals interact and interconnect with the world through socially engaging with others. Against this background, it is therefore fair to contend that the social interaction characteristic inherent in SMM may be construed from the "global and social nature" of social networks sites used by different organisations in the SMM activities. These social network sites provide for the interconnectedness of users (nodes) that circumvents all restrictions imposed by physical boundaries (Maiz et al. 2016).

In relation to bank customers, research reveals that the more conversations exist through social interaction between consumers as well as between the firm and its customers who can be termed nodes, the more product information all parties gain, which may translate to the development of more trust and higher perceived value among them (Chen, 2014). The significance of and relationship between the social interactive nature inherent in SMM, and trust as well as customer satisfaction is supported by Kamtarin (2012:54), who states that "the level of individual participation in an activity has an effect on their levels of trust, customer satisfaction and loyalty to the brand".

\subsubsection{The Theory of Reciprocal Action}

With respect to the Theory of Reciprocal Action (TRA), Park et al. (2014) postulate that "moral norms may dictate that some individual feels obligated to reciprocate the other party's actions based on reciprocal expectation which compels them to do the same". According to Falk and Fischbacher (2000:3) "... a reciprocal action is modelled as the behavioural response to an action that is perceived as either kind or unkind. The more an action is perceived as kind or unkind, the more it will be rewarded or punished, respectively". In this research, the principle of reciprocity is applicable to the SMM context where it is suggested that if (bank) customers or brand communities consider the (bank's) firm's actions and efforts as being inclined towards developing and nurturing online relationships, their loyalty towards the brand or firm also increases together with a positive belief and trust (Park et al., 2014). 
The SET confirms this notion and submits that the building of trust between exchange parties commences with relatively minor transactions which then increase along with the value of the rewards one party receives, which then makes it obligatory for the other party to give a high value reward in return (Homans, 1958). Aligned to the aforementioned argument is the rationale proposed by the Social Penetration Theory (SPT) where Altman and Taylor (1973, cited in Park et al., 2014), postulate that where an association is deemed to be mutually beneficial, parties are most likely to strengthen the relationship. This assertion is also supported by De Wulf et al. (2005) who argue that the users' perception of a company's efforts to preserve and sustain relationships with them on social network sites has a significant positive influence on their perceptions of a firm's relationship investment which may contribute to customer loyalty to the firm's brands.

In summary, it may be noted that through all these theories, it is possible to gain insight into bank customers' behaviour in relation to how SMM can be managed, since it is acknowledged that "customers do not only respond in a rational manner but may be greatly influenced by such intangible, cognitive and emotive" SET factors as trust, perceived benefits, commitment, sociability and levels of social interaction inherent in SMM (Park et al., 2014:68).

It is against the above discussions, the researchers have proposed a conceptual model to better understand the impact of social media marketing on the behaviour of commercial bank customers.

\section{The Conceptual Framework}

\subsection{Social Networking}

Liang et al. (2008) assert that active participation in a social group may generate benefits for individual members, while other individuals in such social groups believe that their contributions may create a good reputation and positively improve their status within the group. Wasko and Faraj (2005) state that in SM communities, the likelihood of improving one's status and reputation may motivate other members to share with others information they consider as important and useful. This manifests through online social activities such as customer-to-customer interactions, blog-writing and the writing of reviews about the firm or brand where status is perceived to be earned through frequent and intelligent answering (So et al., 2014).

Jinyang (2015) and Mahapatra and Mishra (2017) posit that in virtual communities, important and invaluable information is shared both for economic outcomes such as gifts, points or discounts, or for social outcomes such as trust love, support, friendship and self-esteem. In this research, the construct of perceived benefits constitutes three dimensions, namely, informational, social and monetary benefits which are explained in the ensuing discussion.

According to Park et al. (2014), one of the major factors that drive individual participation in virtual communities is information search which involves the exchange of critical material concerning brands and firms (Patterson, 2012), as well as information that helps in purchase decision making (Hutter et al., 2013). Online community members also assist each other with solving brand related issues through question and answer sessions on such platforms as the YouTube. Collectively, these goals can be referred to as informational benefits. Ramanathan et al. (2017) concur and state that customers use SM platforms to regularly exchange their views and ideas on store and brand selection, as well as sharing their experience with their counterparts. In the process, they profoundly influence their counterparts' brand and store options, as well as choices.

Firms such as banks have also become heavily dependent on SM to access and interact with their online communities. Malhotra et al. (2013) suggest that in order to enhance their engagement with their customers in these virtual communities, firms such as banks must create informational value by timeously availing information that customers perceive as topical and important, as well as eliminating that information which could be perceived as irrelevant and unhelpful. It is imperative that bank customers perceive the organization to be promoting their brands and products in an authentic and fair way as this enhances credibility which indirectly contributes to customer satisfaction and loyalty. It is therefore important for commercial banks to establish the influence of informational benefits inherent in SMM on their customers' satisfaction and loyalty.

Park and Kim (2015) opine that one of the key motivational factors behind an individual's active participation in virtual communities is the need for social affiliation with other community members. Wu and Sukoco (2010) emphasise this point by stating that individuals are generally driven to participate in community discourse and interaction largely due to their interest in forging social relationships with others. It may therefore be argued that virtual community members crave for that sense of belonging and identification, which then binds 
them with the rest of the group creating social bonds that promote reciprocity (Chan and Li, 2010). These researchers assert that consumers engage with other members in both online and offline communities mainly because of the perceived social value they derive from such communities, as they communicate and interact with like-minded people, and this includes positive social experiences which promote meaningful relationships. Koning and Murthy (2017) argue that the perceived social value becomes pivotal in influencing community members' participation in virtual networks, especially for poor or disadvantaged customers, who lack reliable and dependable brand or service information. The aforementioned researchers further argue that disadvantaged members of online communities may prefer to interact with well-informed, educated and influential individuals within their social network to obtain important and credible brand or service information.

It is against the above background that this study deems it necessary to have a clear understanding of how the social benefits inherent in SMM impact on commercial bank customers' behaviour.

\subsection{Monetary Rewards}

Ramanathan et al. (2017) state that consumers use SM platforms to share information such as promotional offers and gift vouchers or any price-related promotions with fellow customers within their online communities. This is validated by Hennig-Thurau et al. (2010) who suggest that the need to access and share economic incentives such as exclusive deals, with other community members is another motivating factor for individual participation in virtual networks.

Storm (2015: 37) defines monetary benefits as the "value of gaining promotions, price-discounts, and prizes from contests that a fan can benefit from through the Facebook brand Page", while Men and Tsai (2013:78) describe monetary benefits as the "...participation in online communities where users seek rewards and benefits (e.g. economic incentives such as coupons and promotions) that are constantly shared and distributed through online social networks". Therefore, it is imperative to investigate how monetary benefits inherent in SMM influence bank customers' behaviour.

\subsection{Social Connectedness}

According to Van Bel et al. (2009), social connectedness is "a short-term experience of belonging and relatedness, based on quantitative and qualitative social appraisals, and relationship salience". Baumeister and Leary (1995, cited in Van Bel, 2009:2) state that the "subjective experience of belonging lies at the core of the construct of social connectedness, which has been designed to capture social experiences originating from recent interactions and provision of awareness information". It involves three social outcomes: "the satisfaction with one's social situation, thinking of others and the feeling of being together outside of social contact" (Van Bel et al., 2009:2). As a SM feature, social connectedness exhibits itself through consumers' social experiences as they interact with the firm's SM platforms which creates a sense of belonging and close relatedness to the brand or firm (Riedl et al., 2013). In explaining connectedness as a characteristic of SM, Riedl et al. (2013) argue that the advent of SM has enabled individuals to form online or virtual communities made up of members with common interests and backgrounds who share convergent ideas and views. Research shows that in these communities, SM has allowed for electronic word of mouth which has more impact than offline word of mouth in terms of reach, convenience, connectedness, ubiquity, cost, transparency, conservation and engagement. These online communities, opinion leaders, experts in various fields and authorities wield much influence in terms of drawing users' attention to, and managing, directing and influencing discussions on issues considered to be important and relevant to members (Yan, Mai and Ber, 2011). Due to this immense influence, experts and authorities enlist a great deal of trust and credibility among community members which translates into enhanced trust of the brand or a company's websites.

\subsection{Strength of Ties}

In his seminal work, Granovetter (1973, cited in Liang et al., 2008) explains that peer communication on virtual networks is influenced by the strength of ties, as evidenced by closely knit communities which are closed to outside influences. (Hansen et al., 1999:61) postulates that "the strength of ties is measured by the intensity of social relationships binding community members to each other". The strength of a tie is "determined by the amount of time spent communicating, emotional intensity, intimacy shared and reciprocity; while its measurements include, inter-alia, mutual understanding, influence, individual social skill, connection and network (Liang et al., 2008:54). These researchers further state that the strength of a tie ranges from weak to strong, with stronger ties reflecting similarities in, among others, opinion, benefits, attitudes and strong connections. According to Hansen et al. (1999), strong ties, which are evidenced by frequent interactions and 
closeness among community members, produce high trust, harmonious relationships and an effective exchange of ideas, opinions and information leading to a positive electronic word of mouth (e-WOM). In supporting this observation, Fukuyama (1996) states that the success of an online network such as Facebook depends on the existence of a strong real-world network which allows online community members to reach out and create weak ties while maintaining strong ties. In the process, this encourages social capital formation (Scheepers et al., 2014), which is defined as the resources inherent in social relationship networks such as trust, norms of reciprocity, and social support (Nahapiet and Ghoshal, 1998).

Social capital is an outcome of internal and strong connection found inside a closely-knit exclusive group where both emotional and utilitarian support can be found. Research by Ellison, Steinfield and Lampe (2007) indicates that the higher usage of such SM platforms as FB is strongly related to higher levels of social capital. Huang et al. (2017:43) support this observation by stating that "when colleagues interact through social media, positive bi-directionality perception will allow members to perceive that colleagues are willing to interact with themselves. Even-more, when their problems are well understood and communicated, the individual's acceptance and the sense of trust will affect their trust in the treatment of colleagues." To this end, in this study, it is deemed critical as well to examine how the strength of ties in SMM impacts commercial bank customers' loyalty.

\subsection{Social Interaction}

Tsai and Ghoshal (1998) examined the construct of social interaction in the context of SET and they consider social interaction as a vital conduit which carries and delivers critical resources and information between and among exchange parties. In support of this, Larson (1992) argues that the frequency, intensity and breath of information are functions of the number of partners involved in any exchange, hence the relationship between intensity and breath is directly proportional.

Amongst the key sub-variables that define social interaction is the communication frequency among network members, the strength that characterises the relationship and the time members spend communicating. Baethge et al. (2017), posit that online community consumers disclose and spread their positive and negative opinions, attitudes and preferences towards a brand, product or service through various online platforms such as review websites and social networking sites. It is important to stress that where there are high levels of social engagement and interaction among online customers, the resultant social influence will have a huge impact not only on other customers' views, attitudes and opinions, but on their purchase decisions and intentions (HennigThurau et al., 2010). Baethge et al. (2017) support this observation and state that a dissatisfied customer will generate significantly more negative word of mouth (WOM), compared to positive WOM generated by a satisfied customer. As such it is argued that negative WOM developed during social interactions has a stronger influence on other social exchange partners than a positive WOM (Baethge et al., 2017; Wang, 2010), since customers tend to give more weight and attention to negative information than positive ones (Hennig-Thurau et al., 2010). Thus, it may be argued that both positive and negative social influence channelled through online social interaction have a huge influence on customer responses such as satisfaction, loyalty and repurchase intention, all of which in turn affect a firm's profitability and long-term performance. Strong positive ratings of products or services have a positive impact on the sales of products or services (Clemons, 2009), while negative ratings will enlist a corresponding negative outcome for the company's sales and bottom-line (Romani et al., 2012). The literature suggests that social interactions between marketers and online communities and among SM users, is influenced by a number of factors that include customer engagement, reciprocity and perceived fairness (Hennig-Thurau et al., 2010) and this will be discussed below.

\subsection{Customer Engagement}

The concept 'engagement' can be viewed from a multidisciplinary perspective. The Human-Computer Interaction field considers the psychological aspects the individual exhibits during their interaction with technology, characterised by attention and satisfaction which normally influences and encourages future use (Webster and Ahuja, 2006). The social science space regards engagement as the individual's participation as reflected by their commitment and emotional engagement with the brand, product or service. In the context of this research, customer engagement "entails the interaction and connection between the customer and the firm, between the customer and the brand, and among customers themselves, which makes customers co-producers or co-creators of the product or service" (Webster and Ahuja, 2006:27). Nammir et al. (2012:54) describe customer engagement "as the customer's 'presence' which consists of three levels, namely, physical, emotional and cognitive presence." The above researchers further state that customer engagement as a construct comprises of four sub- variables which are vigour, dedication, absorption and interaction. 
Vigour involves the levels of energy and mental resilience which customers exhibit as they relate with the brand, firm and other customers, and it is this vigour that explains the customers' willingness to invest time and effort in the exchange process, despite any possible challenges or distraction (Nammir et al., 2012). These authors describe dedication as the customers' sense of belonging, that pride, passion and enthusiasm that customers have towards the brand, firm or other customers they interact with, while absorption relates to the levels of concentration customers exhibit when interacting with the brand, firm or other customers which maybe reflected through their happiness and deep affiliation.

Among the characteristics of engagement are elements such as awareness, sensory appeal, feedback, interactivity, perceived control, motivation, interest and affect (Brodie et al., 2011:252). Customer engagement through social media platforms can be measured by behaviour metrics such as the number of pages visited by a user, loyalty of the user to the page, recency, number of comments or shares posted, and editing activity in articles (Peterson and Carrabis 2008; Smith and Gallicano 2015; Halfaker, Geiger, Morgan and Riedl, 2013). It is argued that high levels of customer engagement normally generate increased customer satisfaction and repurchase intention, and decrease negative WOM (Witt and Brady, 2003), which may in turn promote customer loyalty. It is therefore the intention of this research to investigate the influence of customer engagement inherent in SMM on commercial bank customers' behaviour in Zimbabwe.

\subsection{Perceived Reciprocity}

According to Cropanzano et al. (2005), SET stipulates that where interdependent relationships exist, any exchange between parties generally receives a norm of reciprocity. This assertion is rooted in Gouldner's (1960) claim that any favourable treatment that one party receives will obligate them to return the gesture ceteris paribus. In support, Blau (1964, cited in Cropanzano et al., 2005) states that if an individual does something for another, the receiver is obliged to respond in a complementary fashion. More importantly, if an individual's benefit is greater than what they anticipated to receive, a sense of gratitude engulfs them, creating an obligation to reciprocate to the other party.

In SMM, the parties' (that is the firm and its customers) continued ability to interact, share and exchange information, ideas and opinions is largely influenced by trust, reciprocity, perceived fairness and perceived benefits, among other factors (Jiang et al., 2013). When customers consider that their contribution (ideas, information, opinions) are valued and recognised as they interact with the brand, firm or with other customers, they will hold the relationship and exchange in high regard (Gruner and Power, 2017). Jiang et al. (2013) posit that customer reciprocity occurs when communication is more individualised and more frequent, which then enhances perceived relationship quality between the customer and the firm or among customers themselves, thereby strengthening the perceived interpersonal value each party expects out of the exchange. This positive exchange in turn will influence positive results and attitudes such as loyalty and satisfaction (Gruner and Power, 2017). The strong convergence support shown in the preceding discussion makes it imperative for this study to confirm or disconfirm the argument that perceived reciprocity generates positive commercial banks customers' behaviour.

\subsection{Perceived Fairness}

The principle of perceived fairness is derived from SET which postulates that individuals are rational and participate in an exchange largely with the prime objective of obtaining the highest possible benefit (Jiang et al., 2013). The nature of an exchange is based on the assumption that the more that each side invests, the more the other side is obligated to reciprocate since they would perceive the exchange to be based on the concept of fairness. An individual's perception of how fair the exchange process is, has a huge impact on how they respond, react and reciprocate to the other party's offer (Blau, 1964 cited in Jiang et al., 2013). Based on these arguments, the question that begs an answer is how does perceived fairness influence bank customers trust which may then enhance and translate into bank customer loyalty?

\subsection{Trust}

Trust has been empirically tested as a relational variable by researchers who concur with theorists (Morgan and Hunt, 1994) that it (trust) is the most important of the relational exchange determinants. As a construct, trust has been extensively researched with findings linking it to positive outcomes such as job satisfaction (Edwards and Cable 2009), effort and performance (Colquitt et al., 2007), and citizenship behaviours (Mayer et al., 1995 ). Many researchers submit the definition that trust is the willingness to be vulnerable to another, with various dimensions and categorisations (Colquitt et al., 2007; Morgan and Hunt, 1994; Liang et al., 2008). 
McAllister (1995:36) classifies trust into two categories, with cognition-based trust being defined as a "rational evaluation of an individual's ability to carry out obligations; and affect-based trust being an emotional attachment that stems from the mutual care and concern that exist between individuals". It is important to underscore that in as far as SET is concerned, trust in its different forms, is critical to the social exchange process (Blau, 1964), as it creates and maintains exchange relationships which may result in increased customer satisfaction and loyalty, and induces customer repurchase intentions. Lawler and Yoon (1997) argue that pleasure, excitement and happiness tend to promote mutual trust, which in turn has an effect on the mutual success of an exchange since parties progressively acquire experience with one another, thereby boosting interpersonal cooperation. In support of this assertion, Cropanzano et al. (2016) state that if trust exists in an exchange relationship, the parties involved are likely to be willing to be cooperative in their interaction. Thus, positive interpersonal interactions are good determinants of positive attitudes as they motivate exchange parties to have positive behaviours (Spector and Fox, 2010). It is therefore important that this study investigates how customer trust builds and influences customer loyalty.

\subsection{Customer Satisfaction}

Customer satisfaction has been noted as one of the most important outcomes of a positive customer experience, alongside trust, purchase intention, re-purchase intention and loyalty (Meyer and Schwager, 2007; Bansal et al., 2004). Cheung and To (2016) define customer satisfaction as a customer's feelings and attitudes after the consumption or use of a service or product. More importantly, Zatalini and Pamungkas (2017) describe satisfaction as an individual's feeling of pleasure that may influence their intention to buy or use a firm's product or service in the future. Research indicates that satisfied customers share their satisfaction levels with other users of the product or service and hence the firm stands to benefit from such recommendations (Rogerson, 1983 cited in Khan, 2016). It is further argued that satisfied customers exhibit positive post-purchasing behaviour (Fornell, 1992) and therefore it is essential that firms use SM platforms where they can communicate, interact and share their opinions and ideas on company products and services, as this contributes to customer equity which in turn leverages the firm's sales and bottom-line. Previous studies on the relationship between satisfaction and customer behaviour by Bansal et al. (2004) and Cronin et al. (2000, cited in Bassey, 2014), concluded that customer satisfaction has a huge influence on customer retention, while Zhang and Pan (2009) found that there is a direct relationship between customer satisfaction and the profitability of the firm. It thus becomes critical to examine how commercial banks fare in the use of SMM in building customer loyalty and customer repurchase intention through satisfying customers.

\subsection{Customer Loyalty}

Day (1969), cited in DeWitt et al., 2008:69) defines customer loyalty "as a specific state in which the repurchase behaviour is tied to a psychological and emotional attachment of customers toward the brand, product or service". Oliver (1997: 67) considers it "as a deeply held commitment to rebuy, or re-patronize a desired product or service regularly in the future...regardless of situational influences and marketing efforts that potentially cause the switching behaviours". Loyalty should be considered as a combination of attitude and behaviour (Dick and Basu, 1994; Kaur and Soch, 2013). Attitudinal loyalty refers to "the positive personal attitude that a customer holds towards a brand, product or service which normally promotes a superior performance by the firm due to the satisfied customers' positive WOM, a willingness to pay and a likelihood of future patronage (DeWitt et al., 2008:64). Behavioural loyalty is reflected by the customer's action premised on past purchases. It is the readiness of the customer to repurchase and maintain a mutually beneficial relationship which is exhibited by customers being less sensitive to prices, and their willingness to provide feedback without any intention to switch to competitors (Sciarelli et al., 2017). With the advent of digital technologies, firms have embraced the use of customer loyalty programs through various SM platform such as Facebook not only to reward their customers but to generate customer data, influence customer behaviour and to protect market shares. An analysis of the role and impact of bank customer loyalty on bank customer repurchase intention is very central to this study.

\subsection{Customer Repurchase Intention}

According to Chang and Hsu (2016), the firm's future revenue generation capacity, its prospects for continued existence and bottom-line realisation are all functions of customer repurchase intention while the latter is largely influenced by the interaction between consumer mood, customer involvement and the real shopping experience (Ravaglia et al., 2015), as well as how customers evaluate their previous purchase transactions (Bansal et al., 2004). More importantly, customer feedback through online social media platforms significantly impacts on customers' shopping decisions since consumers are increasingly depending on e-WOM in forming 
their impressions, attitudes and opinions towards brands, products or services (Ramanathan et al., 2017). To this end, it is noteworthy that a firm that communicates in a rational and informative manner may contribute significantly to the reduction of uncertainty; doubt and confusion in customers' minds results in decreasing the chances of consumers repurchase intentions. Based on the above, of interest to this study is the need to examine the impact of SET determinants inherent in SMM on commercial bank customers' responses namely customer loyalty, customer repurchase intention and customer satisfaction.

The above theoretical arguments can be consolidated into a conceptual model (Figure 3) which reflects the interconnectedness between and among the various constructs in social media marketing which apply specifically to commercial bank customers.

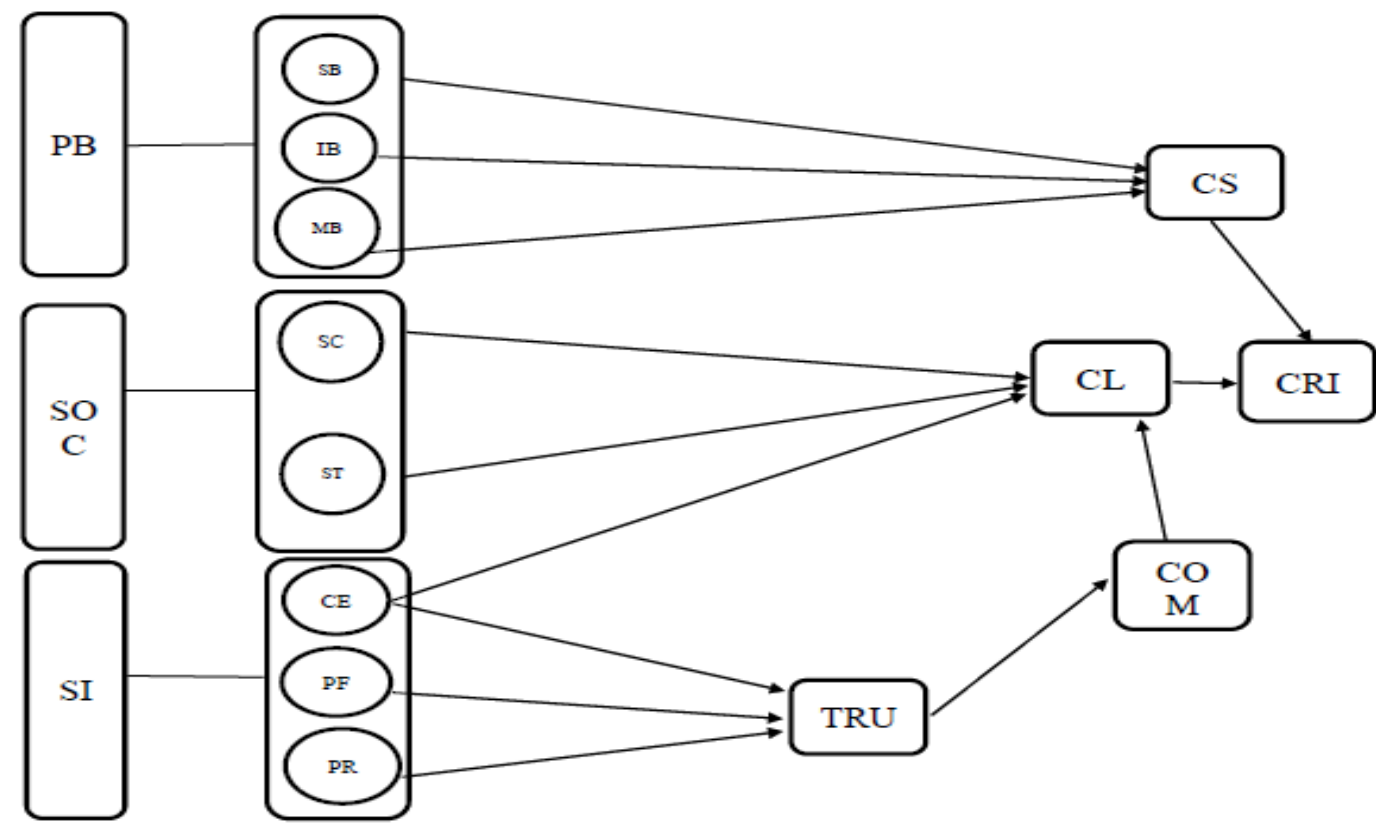

KEY

PB-Perceived Benefits

SOC-Sociability

SI-Social Interaction

SB-Social Benefits

IB-Information Benefits

\begin{abstract}
MB-Monetary Benefits
SC-Social Connectedness

ST-Strength of Ties

CE-Customer Engagement

PF-Perceived Fairness
\end{abstract}

\author{
PR-Perceived Reciprocity \\ CS-Customer Satisfaction \\ CL-Customer Loyalty \\ TRU-Trust \\ COM-Commitment \\ CRI-Customer Repurchase Intention
}

Figure 3. Proposed Conceptual Model

\section{Summary}

It became evident from the literature review, that SM has significantly transformed firm-to-customer and customer-to-customer interactions. SM has empowered the 'new' customer with remarkable influence over and control of the 'conversations' between the organisation and its customers, while the firm has lost the leverage and power previously possessed in the traditional model of interaction. It also became apparent that SMM enables customer engagement, interaction, collaboration and harnessing information for the purpose of marketing of products and services. The main objectives of SMM have been established "as stimulating sales, increasing brand awareness, improving brand image, and generating traffic to online platforms, reducing marketing costs, and creating user interactivity on platforms by stimulating users to post or share content" (Park and Oh, 2012: 68). It may be surmised that while acknowledging the importance of SMM to the banking sector, the impact of SMM on bank customers' behaviour (which in this research refers to customer loyalty, satisfaction and repurchase intention) remains unanswered and requires extensive investigation. An examination on how SET factors (such as trust, social interaction and perceived benefits) which are inherent in SMM motivate or inhibit customer satisfaction, loyalty and repurchase intention warrant scholarly attention. The next chapter will review selected theories from sociology, communication, psychology as well as computer and information sciences, which relate to the dynamic and complex interactions inherent in SM. The chapter will also focus on an analysis 
of the already mentioned determinants inherent in SMM, such as trust, sociability, perceived benefits and social interaction.

This paper specifically reviewed the literature on the Social Exchange Theory (SET) determinants inherent in SMM, such as trust, sociability, perceived benefits and social interaction, and their relationship with, and influence on customer satisfaction, customer loyalty and customer purchase intention will also be examined. Furthermore, selected theories from sociology, communication, psychology as well as computer and information sciences, which relate to the dynamic and complex interactions inherent in social media will be reviewed.

\section{References}

1. Ahmed, R. I. 2017. The influence of perceived social media marketing activities on brand loyalty: The mediation effect of brand and value consciousness, Asia Pacific Journal Of Marketing and Logistics, 29, 1, 129-144

2. Altman, I. and Taylor, D. A. 1973. Social penetration: The development of interpersonal relationships, Oxford, England, Holt, Rinehart and Winston.

3. American Bankers Association, 2017. The state of social media in banking, Cities in a world economy $3^{\text {rd }}$ Ed, Saskia Sassen University Of Chicago, Washington D.C, USA, Sage Publications.

4. Appel, L., Dadlani, P., Dwyer, M., Hampton, K., Kitzie, V., Matni, Z. A., Moore, P. and Teodoro, R. 2014. Testing the validity of social capital measures in the study of information and communication technologies. Information, Communication and Society, 17, 398-416.

5. Ashley, C. and Tracy, T.2015. Creative strategies in social media marketing: An exploratory study of branded social content and consumer engagement. Psychology and Marketing, 32, 15-27

6. Baethge, C., Klier, J., Klier, M., and Lindner, G. 2017. Customers' influence makes or breaks your brand's success story - accounting for positive and negative social influence in online customer networks. Completed Research Paper Thirty Eighth International Conference on Information Systems, South Korea.

7. Blau, P. M. 1964. Exchange and power in social life, USA, Transaction Publishers.

8. Bansal, H. S., Irving, P. G. and Taylor, S. F. 2004. A three-component model of customer commitment to service providers. Journal of the Academy of Marketing Science, 32, 234- 245.

9. Bassey, F. O. 2014. The effect of perceived price fairness on customer satisfaction and loyalty. Master of Science in Tourism Management, Eastern Mediterranean University,

10. Baumeister, R. F. and Leary, M. R. 1995. The need to belong: desire for interpersonal attachments as a fundamental human motivation. Psychological Bulletin, 117, 497-529.

11. Brodie, R. J., Hollebeek, L. D., Juric, B. And Ilic, A. 2011. Customer engagement: conceptual domain, fundamental propositions, and implications for research. Journal of Service Research, 14, 252.

12. Cesaroni, F. M., and Consoli, D. The adoption of social media by micro and small enterprises. In: Mesquita, A. A. P., P, Ed. Proceedings of the 2nd European conference on social media, 9-10 July 2015, Portugal.

13. Chan, K. W. and Li, S. Y. 2010. Understanding consumer-to-consumer interactions in virtual communities: the salience of reciprocity. Journal of Business Research, 63, 1033-1040.

14. Chang, C. M. and Hsu, M. H. 2016. Understanding the determinants of users' subjective wellbeing in social networking sites: an integration of social capital theory and social presence theory. Behavioural Information Technology, 35.

15. Charlesworth, A. 2014. An introduction to social media marketing, UK, Routledge.

16. Cheung, F. Y. M. and To, W. M. 2016. A customer-dominant logic on service recovery and customer satisfaction. Management Decision, 54, 2524-2543.

17. Chikandiwa, S.T., Contogiannis, E. and Jembere, E. 2013. The adoption of social media marketing in south african banks. European Business Review, 25, 365 - 381.

18. Clemons, E. K. 2009. The complex problem of monetizing virtual electronic social networks. Decision Support Systems, 48, 46-55.

19. Colquitt, J. A. 2001. On the dimensionality of organizational justice: a construct validation of a measure. Journal Of Applied Psychology, 86, 386 - 400.

20. Constantinides, E. and Fountain, S. J. 2008. Web 2.0: conceptual foundations and marketing issues. Journal of Direct, Data and Digital Marketing Practice, 9, 231-244.

21. Cropanzano, R., Anthony, E., Daniels, S. and Hall, A. 2017. Social exchange theory: a critical review with theoretical remedies. Academy of management annals, Vol. 11, 1, 479-516.

22. Cropanzano, R., Mitchel, M. S. 2005. Social exchange theory: An interdisciplinary review. Journal Of Management, 31, 874-900. 
23. Curras-Perez, Ruiz-Mafe and Sanz-Blas 2014. Determinants of user behaviour and recommendation in social networks: an integrative approach from the uses and gratifications perspective. Industrial Management and Data Systems, 114, 1477-1498.

24. Das, S. R. and Chen, M. Y. 2007. Yahoo! For Amazon: sentiment extraction from small talk on the web, Management Science, , 53, 1375 - 1388.

25. Dawayan, C. R. and Sondoh, S. L. 2015. Issues and challenges of social media adoption by tourism smes. Global Journal of Business and Social Science Review, 4, 212-219.

26. Day, G. S. 1969. A two dimensional concept of brand loyalty. Journal of Advertising Research, 9, 29-35.

27. De Wulf, K., Odekerken-Schröder, G., Goedertier, F. and Van Ossel, G. 2005. Consumer perceptions of store brands versus national brands. Journal of Consumer Marketing 22, 223-232.

28. Debono, R. 2013. The Effectiveness of social media marketing as a branding tool for hoteliers Bachelor of Arts with honours in Tourism Studies, University Of Malta.

29. Dick, A. and Basu, K. 1994. Customer Loyalty: Toward an integrated conceptual framework, Journal of Marketing Science, 22, 99-113.

30. Edwards, J. R. and Bagozzi, R. P. 2000. On the nature and direction of relationships between constructs and measures. Psychological Methods, 5, 155.

31. Edwards, J. R., and Cable, D. M. 2009. The value of value congruence. Journal of Applied Psychology, 94, 3, 654-677

32. Ellison, Steinfield and Lampe 2007. The benefits of facebook "friends:" social capital and college students' use of online social network sites. Journal of Computing and Mediating Communication, 12, 1143-1168.

33. Emarketer. 2017. [online] Available: www.emarketer.com.

34. Falk, A. and Fischbacher, U. 2000. A theory of reciprocity. University of Zurich: Institute of Empirical Research in Economics.

35. Felix, R., Rauschnabel and P.A, H. C. 2016. Elements of strategic social media marketing: a holistic framework, Journal of Business Research, 70, 118-126

36. Fornell, C. 1992. A national customer satisfaction barometer: the Swedish experience. Journal of Marketing, 56, 6-21.

37. Friedlein, A. 2014. Digital marketing and ecommerce trends and predictions for 2014

38. Gilstrap, J.B., and Collins, B.J. 2012. The importance of being trustworthy: trust as a mediator of the relationship between leader behaviors and employee job satisfaction, Journal of Leadership and Organizational Studies, 19,2, 152-163

39. Godes, D. and Mayzlin, D. 2004. Using online conversations to study word-of-mouth communication. Marketing Science, 23, 545-560.

40. Gouldner, A. W. 1960. The norm of reciprocity: a preliminary statement. American Sociological Review, 161-178.

41. Granovetter, M. 1973. The strength of weak ties American Journal of Sociology, 78., 1360-1380

42. Gruner, R. L. and Power, D. 2018. To integrate or not to integrate? Understanding b2b social media communications. Online Information Review, 42, 1, 73- 92.

43. Hansen, M. T., Nohria, N. and Tierney, T. 1999. What's your strategy for managing knowledge? Harvard Business Review, 77, 106-116.

44. Hennig-Thurau, T. and Klee, A. 1997. The impact of customer satisfaction and relationship quality on customer retention: a critical reassessment and model development. Psychology and Marketing, 14, 737-764.

45. Hennig-Thurau, T., Malthouse, E. C., Friege, C., Gensler, S., Lobschat, L. A. and Skiera, B. 2010. The impact of new media on customer relationships. Journal of Service Research, 13, 311-330.

46. Hong, M. X. 2012. Going social at China's Banks. The Social Banker.

47. Huang, Z. Q., Chang, S. C. A. and Wu, J. H. 2017. A study on the influence of team members' social media interaction perception on employee creativity. American Journal of Industrial And Business Management, 7, 1209-1228.

48. Hutter, K., Hautz, J., Dennhardt, S. and Füller, J. 2013. The impact of user interactions in social media on brand awareness and purchase intention: The case of mini on Facebook. Journal of Product and Brand Management, 22, 342-351.

49. Jiang, W., Wang, G., Bhuiyan, M. Z. A. and Wu, J. 2016. Understanding graph-based trust evaluation in online social networks: Methodologies and challenges. Acm Computing Surveys (Csur), 49, 10.

50. Jinyang, L. 2015. Knowledge sharing in virtual communities: A Social Exchange Theory Perspective. Journal of Industrial Engineering and Management, 8 170-183.

51. Kamtarin, M. 2012. The effect of electronic word of mouth, trust and perceived value on 
behavioral intention from the perspective of consumers. International Journal of Academic Research in Economics and Management Sciences, 1, 56.

52. Kane, G. C. 2015. Enterprise Social Media: Current capabilities and future possibilities. Mis Quarterly Executive, 14, 1-16.

53. Karikari, S., Osei-Frimpong, K., and Owusu-Frimpong, N. 2017. Evaluating individual level antecedents and consequences of social media use in Ghana. Technological Forecasting and Social Change, 123, 68-79.

54. Kim, D. 2016. Value ecosystem models for social media services. Technological Forecasting and Social Change, 13-27.

55. Koning, A. and Murthy, G. 2017. Customer empowerment in finance: why greater choice and control for poor customers is better for business and will help achieve financial inclusion. Perspectives, 3.

56. Kumar, V., Bhaskaran, V., Mirchandani, R. and Shah, M. 2013. Practice prize winner-creating a measurable social media marketing strategy: increasing the value and roi of intangibles and tangibles for hokey pokey. Marketing Science, 32, 194-212.

57. Lai, C., Singh, B., Alshwer, A. A. and Shaffer, M. A. 2014. Building and leveraging interpersonal trust within and across MNE subsidiaries: A Social Exchange Perspective. Journal of International Management, 20, 312-326.

58. Lambe, C. J., Wittmann, C. M., and Spekman, E. R. 2001:26. Social exchange theory and research on business-to-business relational exchange, Journal of Business-To-Business Marketing, 8, 1-36.

59. Larson, A.1992. Network dyads in entrepreneurial settings: a study of the governance of exchange relationships. Organization Science, 37, 76-104.

60. Lawler, E. J. and Yoon, J. 1997. Structural power and emotional processes in negotiation: a social exchange approach. Thousand Oaks, CA: Sage.

61. Liang, T.-P., Liu, C.-C. and Wu, C.-H. 2008. Can Social Exchange theory explain individual knowledge-sharing behavior? a meta-analysis. Icis 2008 Proceedings, 171.

62. Lim, J., Lim, K. and Heinrichs, J. H. 2014. Gender and mobile access method differences of millennials in social media evaluation and usage: an empirical test. Marketing. Management Journal, 24, 124-135.

63. Liu, M. T., Brock, J. M., Chu, R. and Tseng, T. H. 2013. Perceived benefits, perceived risk, and trust influences on consumers' group buying behaviour. Asia Pacific Journal of Marketing and Logistics, 25, 225-248

64. Maiz, A., Maiz, A., Arranz, N., Arranz, N., Fdez. De Arroyabe, J. C. and Fdez. De Arroyabe, J. C. 2016. Factors affecting social interaction on social network sites: The Facebook case. Journal of Enterprise Information Management, 29, 630-649.

65. Malhotra, N. K. and Birks, D. F. 2006. Marketing Research, An Applied Approach, Harlow Uk, Pearson Education.

66. Manyang, M. G. 2017. The influence of social media platform usage on customer equity. Auckland University of Technology.

67. Mayer, R. C., Davis, J. H., and Schoorman, F. D. 1995 An integrative model of organizational trust. The Academy of Management Review 20,709-734.

68. Mayfield, A. 2008. What Is Social Media?, Uk, Crossing Ltd.

69. Men, L. R. and Tsai, W. 2013. Beyond liking or following: understanding public engagement on social networking sites in China. Public Relations Review, 39, 13-22.

70. Morgan, R. M. and Hunt, S. D. 1994. The commitment-trust theory of relationship marketing. Journal of Marketing, 58, 20-38.

71. Mutero, W. N. 2014. Effect of social media interactions on financial performance of commercial banks in Kenya. Masters' Thesis, University Of Nairobi.

72. Nahapiet, J. and Ghoshal, S. 1998. Social capital, intellectual capital, and the organizational advantage. Academic Management. Review, 23.

73. Nammir, D. S. S., Marane, B. and Ali, A. M. 2012. Determine the role of customer engagement on relationship quality and relationship performance. European Journal of Business and Management, 4, 27-36.

74. Ngai, E.W.T., Tao, S.S.C, and Moon, K.K.L. 2015. Social Media Research: Theories, Constructs, And Conceptual Frameworks. International Journal of Information Management, 35, 33-44.

75. Oliver, R. L. 1997. Varieties of value in the consumption satisfaction response. Advances In Consumer Research, 23, 247-254.

76. Park, H. and Kim, Y. 2015. Can a fashion brand be social?: The role of benefits of brand community within social network sites. Journal of Global Fashion Marketing, 6 75-86.

77. Park, J. and Oh, I. 2012. A case study of social media marketing by travel agency: The salience of 
social media marketing in the Tourism Industry. International Journal of Tourism Sciences, 12, 93-106.

78. Park, M.-S., Shin, J.-K. and Ju, Y. 2014. The effect of online social network characteristics on consumer purchasing intention of social deals. Global Economic Review, 43, 25-41.

79. Patterson, P. G. and Spreng, R. A. 1997. Modelling the relationship between perceived value, satisfaction and repurchase intentions in a business-to-business, services context: An empirical examination. International Journal of Service Industry Management, 8, 414-434.

80. Ramanathan, U., Subramanian, N. and Parrott, G. 2017. Role of social media in retail network operations and marketing to enhance customer satisfaction. International Journal of Operations and Production Management, 37, 105 - 123.

81. Rauniar, R., Rawski, G., Yang, J. and Johnson, B. 2014. Technology Acceptance Model (TAM) and social media usage: an empirical study on Facebook. Journal of Enterprise and Information Management, 27, 6-30.

82. Ravaglia, V., Brivio, E. and Graffigna, G. 2015. Engaging consumers via twitter: Three successful communicative strategies. maximizing commerce and marketing strategies through microblogging. United States of America: Business Science Reference, 91-109.

83. Rogerson, W. P. 1983. Reputation and product quality. The Bell Journal of Economics, 508-516.

84. Romani, S., Grappi, S. and Dalli, D. 2012. Emotions that drive consumers away from brands: measuring negative emotions toward brands and their behavioral effects. International Journal of Research In Marketing 29, 55-67.

85. Saridakis, G., Benson, V., Ezingeard, J.N., and Tennakoon, H. 2016. Individual information security, user behaviour and cyber victimisation: An empirical study of social networking users. Technological Forecasting Social Change, 102, 320-330.

86. Scheepers, H., Scheepers, R., Stockdale, R. and Nurdin, N. 2014. The dependent variable in social media use. Journal of Computer Information Systems, 54, 25-34.

87. Sciarelli, M., Nagm, A., Dakrory, M., Tani, M. and Khashan, M. A. 2017. Mediating service recovery satisfaction in the relationship between internet service recovery and customer loyalty. International Journal of Business and Management, 12.

88. Scott, J. 2012. Social Network Analysis, UK, Sage.

89. Shafie, L. A., Mansor, M., Osman, N., Nayan, S. and Maesin, A. 2011. Privacy, trust and social network sites of university students in Malaysia. Research Journal of International Studies, 20, 154-162.

90. Spector, P. E. and Fox, S. 2010. Theorizing about the deviant citizen: an attributional explanation of the interplay of organizational citizenship and counterproductive work behavior. Human Resource Management Review, 20, 132-143.

91. Stanic, N. and Hansson, L. 2017. Do big laughs and positive attitudes sell? An examination of sponsored content on you tube, and how entertainment and attitude influence purchase intentions in millennial viewers. International Marketing Programme, Bachelor Thesis University of Halmstad.

92. Stelzner, A. M. 2017. Social Media Marketing Industry Report, Available at http://www.socialmediaexaminer.com/report.

93. Storm, M. 2015. Factors influencing involvement, brand attachment and brand loyalty on facebook brand pages. Master Thesis: MSc in EBA, Branding and Communications Management, Copenhagen Business School.

94. Thoring, A. 2011. Corporate tweeting: Analyzing the use of twitter as a marketing tool by UK trade publishers. Publishing Research Quarterly, 27, 141-58.

95. Tsai, W. and Ghoshal, S. 1998. Social capital and value creation: the role of intrafirm network, Academy of Management Journal, 41, 464-476.

96. Van Bel, D. T., Smolders, K. C. H., Ijsselsteijn, W. A. and De Kort, Y. A. W. 2009. Social Connectedness: concept and measurement, In: Eindhoven University of Technology (Ed.) Human Technology Interaction Group, Eindhoven, The Netherlands.

97. Van Deventer, M., De Klerk, N. and Bevan-Dayesha, A. 2017. Antecedents of attitudes towards and usage behavior, Banks and Bank Systems, 12, 20.

98. Wang, P. 2010. Chasing the hottest it: effects of information technology fashion on organizations. Mis Quarterly, 34, 63-85.

99. Wasko, M. M., and Faraj, S. 2005. "Why should I share? Examining social capital and knowledge contribution in electronic networks of practice," Mis Quarterly 29, 35-57.

100. Wu, W. and Sukoco, B. M. 2010. Why Should I Share? Examining Consumers' Motives And Trust On Knowledge Sharing. Journal of Computer Information Systems, 50.

101. Yang, C., Hsu, Y.-C., and Tan, S., 2010. Predicting the determinants of users' intentions for using 
You tube to share video: moderating gender effects. Cyber-Psychology Behaviour Social Network, 13.

102. Zatalini, M. A. A. and Pamungkas, T. N. 2017. exploring the success factors of e-crm implementation on B2C e-commerce: Satisfaction and loyalty a conceptual framework. Journal of Business Economics, 22, 15-22.

103. Zhao, X., Tang Q., Liu S and Liu F. 2016. Social capital, motivations, and mobile coupon sharing,. Industrial Management and Data Systems, 116, 188 - 206. 